\title{
Local Climate Forcing and Eco-Climatic Complexes in the Wooded Savannah of Western Nigeria
}

\author{
Mayowa Fasona $^{1}$, Mark Tadross ${ }^{2}$, Babatunde Abiodun $^{3}$, Ademola Omojola $^{4}$ \\ ${ }^{1,4}$ Department of Geography, University of Lagos, Lagos, Nigeria; ${ }^{2,3}$ Climate Systems Analysis Group, Environmental and Geo- \\ graphical Sciences Department, University of Cape Town, Cape Town, South Africa. \\ Email: mfasona@unilag.edu.ng, \{mtadross, babiodun\}@csag.uct.ac.za, aomojola@unilag.edu.ng
}

Received April 15 $5^{\text {th }}, 2011$; revised May 15 ${ }^{\text {th }}, 2011$; accepted June $1^{\text {st }}, 2011$.

\begin{abstract}
Many climate impact applications are sensitive to local differentials in the climate system. This study investigates how eco-geographic factors influence the local climate and propagate eco-climatic complexes that vary spatio-temporally. Local geography data including elevation, slope, aspect, rainfall, temperature, vegetation, population density, and soil potential for agriculture were integrated and analyzed using geographic information system and principal component analysis. The result was profiled for local climate drivers and associated spatial structures in present and future climate (2046-2065) scenarios. The results suggest a local climate system driven by the coupling between terrain, rainfall and temperature in all seasons. In the present climate, this coupling creates eco-climatic complexes that extend from the southeast to northwest corridor in all seasons except June-July-August (JJA) when it is shifted to the northeast axis. This pattern is projected to continue in the future climate scenario, but its spatial influence and intensity would weaken around the northwest axis and rainfall will become less significant in the system in JJA. The clustering of rural settlements these complexes suggests the climate-positives produced by the system significantly support rural livelihoods. Thus, these eco-climatic complexes represent climate sensitive natural resource systems that should be targeted as a fulcrum for climate change mitigation and adaptation in the wooded savannah.
\end{abstract}

Keywords: Climate Change, Geographic Factors, Eco-Climatic Complex, GIS, PCA, Adaptation, Savannah, Nigeria

\section{Introduction}

Climate change is expected to have significant impact on the terrestrial ecosystems and biodiversity. Developing countries of Africa have low adaptive capacity because of low level of technology and preparedness. Most of these countries also depend on rain-fed agriculture and the natural resource stock which make them severely vulnerable to climate change. The arid and semi-arid regions of West Africa (i.e. the Savannah and Sahel) harbour large population. This accelerates land transformation, degradation and increase resource conflicts. These conflicts may become fiercer in future as these regions have been predicted to get drier. Depending on the emission scenario current temperatures are predicted to rise in the order of 1.4 to $5.8^{\circ} \mathrm{C}$ by 2100 [1]. Long term rainfall signals have already become more erratic in space and time distribution [2-4], whereas only $3.7 \%$ of the total agricultural land in the entire sub-Saharan Af- rica is irrigated [5]. Rainfed agriculture is the major source of livelihood for large rural population in the $\mathrm{Ni}$ gerian savannah $[3,6,7]$. Thus, the water footprint may become more critical in defining the future pattern and trajectory of settlements and agrarian land uses and the concomitant water challenge may overwhelm current traditional agriculture and water management practices.

A degree of local forcing that varies by region and season complements synoptic-scale forcing to influence local climate [8]. Local perturbations including terrain, land cover, and land-water boundary often exert strong influence on the local climate and create eco-climatic structures or complexes that support the natural resource capita on which livelihoods of rural population thrive. The influence of local perturbation tends to occur at relatively fine resolution that cannot be captured by global and most regional climate models. The degree and extent to which these processes can feedback to impact the local climate still represents an element of uncertainty in cli- 
mate projections [8]. Global and regional climate models provide insights into dynamic interaction between land surface and atmospheric processes which drive global and regional climates. But their relatively coarse resolutions often mask large differentials in local forcing including terrain, land cover, agricultural practices, energy policies and socio-economic orientations and details about local scale circulation and perturbation induced by landscape complexity are often eliminated [9-11]. Many impact applications including place-based and context-specific adaptation strategies, ecosystems management, and local mitigation actions are very sensitive to fine scale climate variations that are parameterized in coarse scale models. They require the equivalent of point climate observation. The West Africa region is part of those regions around the world with highly variable climate on seasonal and decadal time scales [11]. The mesoscale convective process (MCS) relies on the complexity in terrain and land cover to propagate and accounts for over $75 \%$ of rainfall received in the West Africa savannah [12]. Understanding the nature and role of such local scale forcings is important for planning strategies for climate adaptation and local level mitigation in the Nigerian savannah.

Empirical downscaling is one way to generate point scale data that captures fine scale variations in local climate. It is a widely used technique for exploring regional and local-scale response to global climate change as simulated by comparatively low-resolution global climate models (GCM). It represents the cross-scale relationships between the larger scale circulation from the GCM and local climate responses based on the premise that the local-scale climate is in some measure a response to the larger, synoptic-scale forcing. Station observational data are used to derive a relationship between the synoptic-scale and local climates which can then be used with comparable resolution fields of a GCM to generate information on the local climate consistent with the GCM forcing $[8,13]$. Empirical downscaling is important for generating regional and local scale scenarios of future climate to make climate change information available for impacts and vulnerability assessments, policy formulation, and climate change adaptation at regional and local scales. It has the advantage to downscale to point scales which matches the observational data characteristics. It also provides regional detail that is consistent with the actual spatial gradients over the region. However, the downscaling is forced by GCMs which means inherent errors in the GCMs data is also transferred into the downscaled data. In addition, because the possibility of going beyond original scale of data is limited, the downscaled data cannot be regarded as a complete substitute for fine scale climate measurements obtained across space. The evaluation of the extent to which local forcings will interface with the climate system and the concomitant spatial influence produced is a key question addressed in this study. Downscaled climate data can be integrated and analyzed with the drivers of the local climate system and this enables their spatial pattern of influence and impact on the local climate system to be deciphered and quantified. We present evidence that local geographic forcings including terrain and land cover have the potential to influence the local climate system across space and seasons and determine spatial patterns of climate-positives and eco-climatic complexes that produce the natural resource capita which supports livelihood systems across the wooded savannah of western Nigeria.

\section{Materials and Methods}

\subsection{Regional Setting}

The study area is roughly defined by Latitudes $8^{\circ}$ to $9^{\circ} 15^{\prime}$ North and Longitudes $3^{\circ} 50^{\prime}$ to $5^{\circ} 50^{\prime}$ East. It covers about $40,000 \mathrm{~km}^{2}$ in western Nigeria, extending from the border with Benin Republic in the west to the Niger floodplains in central Nigeria covering parts of Oyo, Kwara, Kogi, Niger, Ekiti and Osun States (Figure 1). The study area is covered by the wooded savannah ecology which approximates the transitional zone between the southern rainforest and the northern grassland savannah. Average elevation is about $300 \mathrm{~m}$ but outcrops rising above $500 \mathrm{~m}$ in the eastern axis. Vegetation consists of mixture of trees and grasses, as well as moist peri-forest mixed with savannah of anthropic degradation and patchy landscape $[14,15]$. Generally, the area is characterized by a sub-humid Koppen's Aw climate [16]. Annual rainfall received falls between $900 \mathrm{~mm}$ and $1300 \mathrm{~mm}$ and mean maximum temperature range is between $28^{\circ} \mathrm{C}$ and $36^{\circ} \mathrm{C}$ with peak temperature occurring around February and March. The southern part shares the bimodal rainfall pattern of the southern rainforest belt with peaks in mid June to July and September. The highest monthly rainfall occurs in September as opposed to July for the rainforest belt. Rainfall is the most critical limiting factor of human activity in the Nigerian Savannah. Prolonged change in quantity and regime of rainfall is an index of climatic variability and change. Monsoonal wind and MCS are the dominant rain producing forces over the region. The MCS predominates and produces over $75 \%$ of rainfall received [12]. Population density is high and a poverty-environment linkage is very strong. Survival for large rural population depends on small-holder rainfed agriculture $[3,6,7]$ and the natural capital contributes significantly to human well-being [11]. The study area is important for root, tuber and cereal cultivation. Intense 

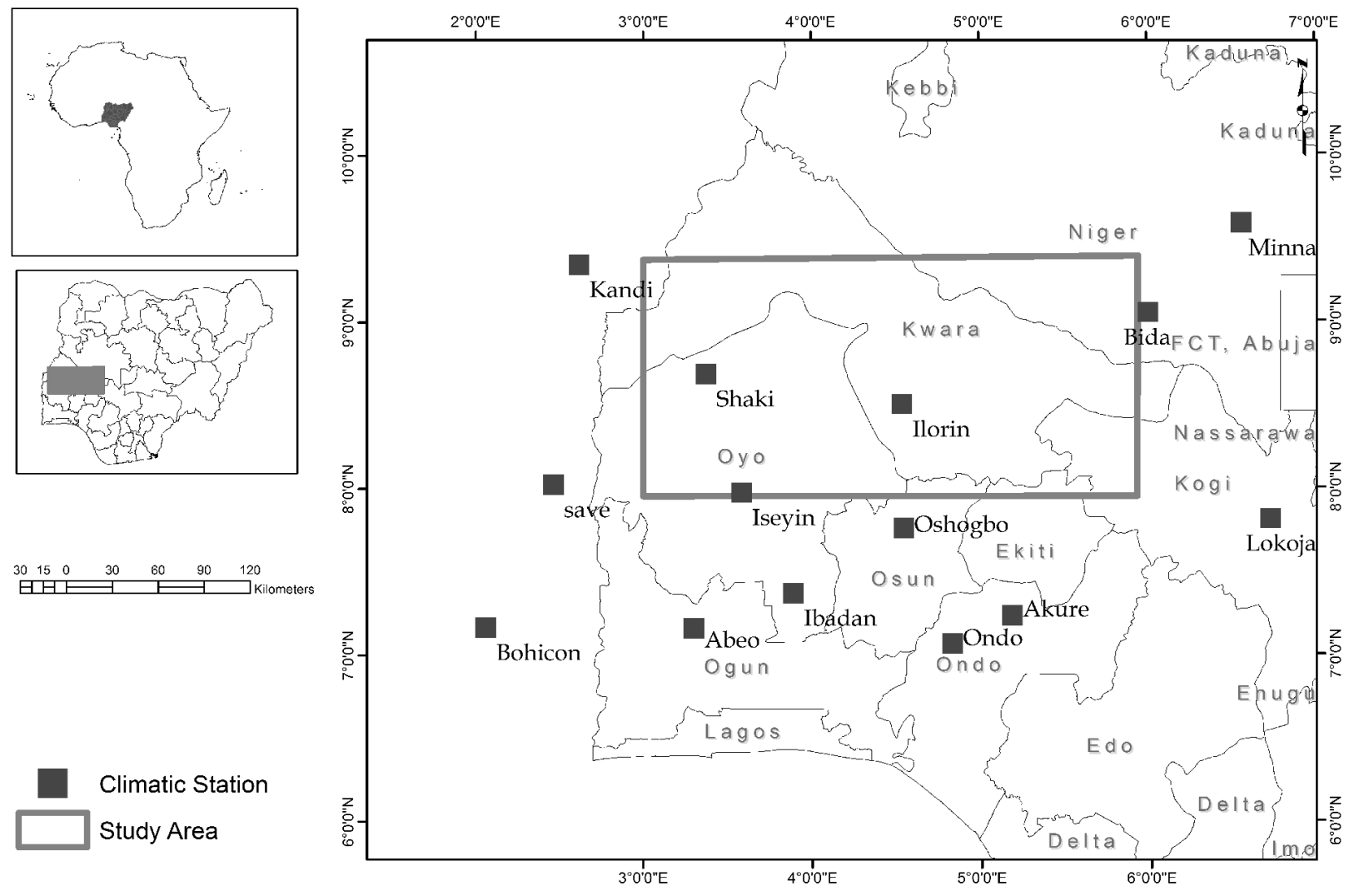

Figure 1. Study area and observation stations.

land use pressure has increased the frequency of savannah fire, forest conversion to agricultural land, and incursions into marginal riparian forests. Uncontrolled harvesting of trees for fuel-wood and charcoal are important livelihood activities $[17,18]$. Due to its large pasture undergrowth, the study area has in recent years become important for extensive grazing for migrating pastoralists. This has increased the frequency of land resource conflict [19-21].

\subsection{Data and Data Sources}

\subsubsection{NDVI}

Dekad 2 long term mean (1982-2008) seasonal normalized difference vegetation index (NDVI) data for January, April, July, and October were accessed from the archive of the Famine Early Warning Systems Network (FEWS-NET) African Data Dissemination Service ${ }^{1}$. The NDVI is derived from data collected by National Oceanic and Atmospheric Administration (NOAA) Advanced Very High Resolution Radiometer (AVHRR) satellites, and processed by the Global Inventory Monitoring and Modeling Studies Group (GIMMS) at the National Aeronautical and Space Administration (NASA). The

\footnotetext{
${ }^{1}$ http://earlywarning.usgs.gov/adds/imgdatas2.php?imgtype=nd\&extent $=\mathrm{W}$
}

NDVI is calculated from the near-infrared (NIR) and visible (VIS) wavelengths of the AVHRR sensor using the following algorithm:

$$
\mathrm{NDVI}=(\mathrm{NIR}-\mathrm{VIS}) /(\mathrm{NIR}+\mathrm{VIS})
$$

The NDVI (also referred to as NDVI-g) dataset derived principally from NOAA-17 inter-calibrated with NOAA-16 and previous NDVI products were also inter-calibrated with SPOT-Vegetation NDVI [22-25]. The spatial resolution of the NDVI data is $8 \mathrm{~km}$ in both $X$ and $Y$ directions and its was reprojected for overlay with other datasets to UTM-31 and WGS spheroid from its original Albers Equal Area Conic and Clarke 1866 spheroid. The NDVI computed data range of -1.0 to +1.0 original scaled to the range of 0 to 200 (where computed -1.0 equals 0 and computed 0 equals 100 and computed 1.0 equals 200) was re-scaled to the normal NDVI range of 0 to 1 using the straight line function:

$$
X=\frac{Y}{100}-1
$$

where $X$ is the rescaled NDVI value and $Y$ is the value in the range 0 to 200 .

The close coupling between rainfall and the growth of vegetation make it plausible to utilize NDVI data as 
proxy for land surface response to precipitation variability and changes in the biophysical properties of vegetation [25-27].

\subsubsection{Terrain}

Terrain data was extracted from the 3 arc-second elevation data from the Shuttle Radar Topography Mission (SRTM) obtained in February 2000 and accessed from the archive of the global land cover facility ${ }^{2}$. The world reference systems (WRS-2) scenes SRTM_ffB03, p190r054 and p190r054 were downloaded and processed to obtain derivatives including contour and spot heights, slope, and aspect.

\subsubsection{Climate}

Data for historical daily rainfall and maximum temperature (1960 to 2005) for 12 climatic stations around the study area was sourced from the Nigerian Meteorological Agency (NIMET) in Lagos. Because the study area is adjacent to the Nigeria/Benin Republic border, rainfall and maximum temperature data was also sourced for 3 adjacent stations in Benin Republic from the portal of the Climate Systems Analysis Group (CSAG) of the University of Cape Town to improve the surface interpolation process. Statistical downscaling of the climate data was carried out in CSAG. The statistical downscaling technique employed matching of GCM data with self organized map (SOM) characterization of atmospheric states and forced by SRES A2 emissions scenario (8,Hewitson and Crane 2006). The driving GCMs were adopted from the Coupled Model Intercomparison Project Phase Three (CMIP3) archive ${ }^{3}$, which makes statistical downscaling possible for the non-seamless periods 2046-2065 (near future) and 2081-2100 (far future) only. The statistical downscaling process reproduced the observational data and also generated both near-future and far-future projections for $10 \mathrm{GCMs}$ plus NCEP reanalysis. Studies that compare climate model output often use ensemble sets of all the models. A comparability study of 18 GCM outputs (including all the 10 generated by the downscaling process) at the process level by [28] suggests that the MRI CGCM 2.3.2 model provides the most reliable simulation of the twenty-first century climate over West Africa. The MRI CGCM 2.3.2 model was thus adopted to characterize the future climate. The comparison between the model output and the observation data and NCEP reanalysis suggests a significant agreement in spatial and temporal pattern of rainfall and maximum temperature across the study area.

\subsubsection{Other Datasets}

Data on forested lands, protected areas, disturbance index,

\footnotetext{
${ }^{2}$ http://www.landcover.org/data/srtm/

${ }^{3} \mathrm{http}: / /$ www.pcmdi.1lnl.gov/projects/cmip/Table.php
}

potential of soils for agriculture, and population density were also developed and integrated. Forested and protected areas were extracted from Landsat TM and $\mathrm{ETM}^{+}$ data. Disturbance indices were computed by criteria evaluation of 12 land cover categories derived from the Landsat imageries. The land cover categories were analyzed according to current state and the extent to which they have been, or are likely to be impacted by human activity. Soil data extracted from the 1:650,000 digital Soils map of western Nigeria sourced from Soils Survey Division of the Ministry of Agriculture and Natural Resources was analyzed for the ability of each pedologic unit to support crop production. Population density data was computed at local government level using data from the 2006 census collated from the National Population Commission.

\subsection{Procedure}

The GIS as a tool for data integration and analysis supports the building of multiple spatial data layers. Features extracted and derivates generated from all data layers are integrated to generate composite results that reveal spatial pattern and processes that are not discernable in individual data layers. The datasets were analyzed to produce gridded derivatives which were integrated into a common GIS database for collocation analysis (Figure 2). The output from the gridded derivatives was exported in ASCII text to statistical software and subjected to principal component analysis (PCA). The seasonal correlations and principal factors were generated and the result was transferred back into GIS for spatial interpolation to derive PCA maps. PCA is an exploratory multivariate statistics that transforms series of variables into a set of components that are orthogonal in both time and space and ordered them in terms of the amount of variance they explain from the series. It is a powerful technique for analyzing variability over space and time [29] and very effective in organizing the underlying sources of variability in data. PCA has been used in related studies on variability in data with climatic and ecological significance and air pollution [30,31], biological diversity $[32,33]$, groundwater and geochemical data variability [34,35], and sources of heavy metals in soil [36].

The seasonal NDVI data produced 798 grid data points which was adopted as the frame for extracting point values (in ASCII) from all the other gridded datasets (rainfall, maximum temperature, aspect, slope, contour, agricultural potential of soils, population density, protected areas, forested areas, and disturbance indexes). The ASCII values extracted were digitally written into the attribute files of the seasonal NDVI data. This process produced a collocated attribute data tables with data fields for the seasonal NDVI and all other datasets. This ex- 


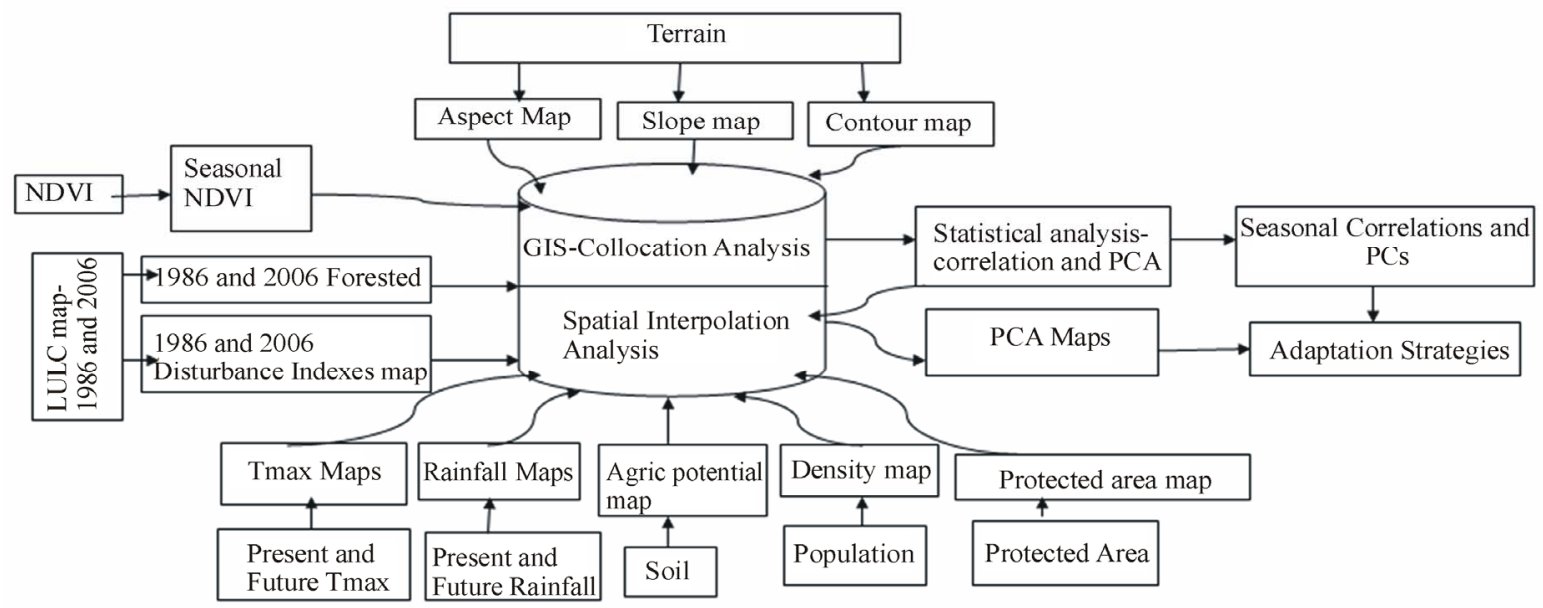

Figure 2. The framework for integration of eco-geographic variables for PCA.

tended attribute data files were imported into STATISTICA $^{\circledR} 9$ software ${ }^{4}$ and subjected to PCA. With the eigenvalues cut-off set at 1 , the correlation matrix option produced standardized PCA. The slope of the scree plot was used to decide the number of factors to retain in each case thereby eliminating inconsequential principal components. Factor coordinates for all cases were transferred into GIS and PCA surfaces were generated using the inverse distance weights (IDW) spatial interpolation algorithm.

Efficient computation of PCA is done with matrix algebra and starts with a matrix of inter-correlations which produces standardized PCA. Data reduction is achieved by finding linear combinations (principal components) of the original variables which account for as much of the original total variance as possible given by:

$$
\mathrm{PC}_{i}=a_{1 i} \mathrm{~V}_{1}+a_{2 i} \mathrm{~V}_{2}+\cdots \cdots+a_{n i} \mathrm{~V}_{n}
$$

where $\mathrm{PC}_{i}$ is principal component $i$ and $\mathrm{a}_{1 i}$ is the loading (correlation coefficient) of the original variable $\mathrm{V}_{1}$ [31].

The successive linear combinations are extracted in such a way that they are uncorrelated with each other and account for successive smaller amounts of total variance [31].

\section{Results}

\subsection{Pattern of Feedbacks Between Climate and Eco-Geographic Factors}

The feedbacks and associated spatial patterns created by the interaction between climatic elements and eco-geographical variables are critical for planning adaptation to climate change especially at local levels. The regional climate of the wooded savannah is strongly influenced the MCS, a coupled system of local processes including

\footnotetext{
${ }^{4}$ www.statsoft.com
}

the influence of terrain, land-cover and moisture gradient.

The seasonal correlations across space between rainfall and maximum temperature on one hand, and NDVI and elevation on the other are shown on Tables 1 and 2 respectively for present and future climates.

NDVI is positively correlated with elevation $(r=0.56$, $\mathrm{p}<0.01)$ and rainfall $(\mathrm{r}=0.53, \mathrm{p}<0.01)$ in MarchApril-May (MAM). MAM represents the onset of the rains when the wooded savannah recovers after the dry period of December-January-February (DJF). The more rainfall experienced during this period the greener the region becomes. Elevated areas normally have higher chance of receiving early rainfall due to the strong effect of MCS which requires the lifting force provided by terrain to produce rain. This may also explain why some areas around relatively rugged terrain are wetter than the surrounding areas.

This well known relationship between terrain and climate is also demonstrated by the positive correlation between elevation and rainfall and the negative correlation of elevation with temperature (in all seasons) except in June-July-August (JJA) when the pervading system is reversed. Thus rainfall shows strong negative correlation with elevation $(\mathrm{r}=-0.62, \mathrm{p}<0.01)$ and strong positive correlation with Tmax $(\mathrm{r}=0.76 \mathrm{p}<0.01)$ in JJA. This strongly suggests the dominance of the West African monsoon (WAM) system in JJA. Normally, the MCS requires a local forcing such as higher altitude or vegetation to lift the gathered moisture to saturation, condensation and precipitation stages. However, in JJA because of the influence of the WAM system which predominates during this period, the influence of MCS and the local forcings are weakened because the atmosphere is saturated already. Hence, less rainfall is produced by the local systems even at higher altitudes. 
Table 1. Correlation of climate and eco-geographic variables for present climate.

\begin{tabular}{|c|c|c|c|c|c|}
\hline Variables & Season & NDVI & Elevation & Rain & Tmax \\
\hline \multirow{4}{*}{ NDVI } & DJF & & -0.161 & -0.184 & 0.298 \\
\hline & MAM & & 0.563 & 0.530 & -0.382 \\
\hline & JJA & & -0.073 & 0.347 & 0.250 \\
\hline & SON & & 0.261 & 0.023 & -0.089 \\
\hline \multirow{4}{*}{ Elevation } & DJF & & & 0.678 & -0.774 \\
\hline & MAM & & & 0.499 & -0.670 \\
\hline & JJA & & & -0.624 & -0.641 \\
\hline & SON & & & 0.151 & -0.666 \\
\hline \multirow{4}{*}{ Rain_ } & DJF & & & & -0.777 \\
\hline & MAM & & & & -0.733 \\
\hline & JJA & & & & 0.759 \\
\hline & SON & & & & -0.096 \\
\hline
\end{tabular}

All correlations significant at the 0.01 level (2-tailed).

Table 2. Correlations of climate and eco-geographic variables for future climate (2046-2065).

\begin{tabular}{ccccc}
\hline Variables & Season & Elevation & Rain & Tmax \\
\hline \multirow{4}{*}{ Elevation } & DJF & & 0.739 & -0.761 \\
& MAM & 0.620 & -0.739 \\
& JJA & 0.034 & -0.683 \\
& SON & 0.389 & -0.756 \\
& DJF & & -0.887 \\
Rain & MAM & & -0.658 \\
& JJA & & 0.351 \\
& SON & & -0.431 \\
\hline
\end{tabular}

All correlations significant at the 0.01 level (2-tailed).

The WAM system is essentially driven by land-ocean pressure differential driven by heating on the land. The sun is overhead on the tropic of cancer in June (boreal summer) and overhead around the West Africa savannah in July/August on its way back to the equator. The savannah thus receives direct insolation which creates a low pressure zone on land. This low pressure drives the monsoon from the ocean to the land to produce rainfall, hence the positive correlation between rainfall and temperature. This is especially significant because it represents a reversal of the existing system dominated by MCS and allows areas around the inland basins and the northeast axis to experience maximum rainfall. The system is reversed again in September-October-November (SON) and this appears to be responsible for the strongly delineated bimodal rainfall peak received in the region.

The strong association of rainfall and temperature with terrain in DJF, MAM and SON is expected to continue in future scenario. However, the no correlation $(\mathrm{r}=0.03, \mathrm{p}$ $<0.01)$ and weak positive $(\mathrm{r}=0.35, \mathrm{p}<0.01)$ association between rainfall and temperature respectively with terrain in JJA suggest that the coupling between rainfall, temperature and terrain will become weaker in future scenario. This may have serious implications for rainfall in the inland basins around the northeast axis which rely on the reversal of the system in JJA.

\subsection{Analysis of the Controlling Systems}

Eighteen (18) variables (15 for future climate) were generated, integrated and analyzed. The target is to identify the combination of factors (i.e. factors coupled into systems) that have impacts on the local climate. Tables 3 and $\mathbf{4}$ show the rotated (varimax with Kaiser Normalization) results of component matrix generated through correlation matrix for the present and future climates respectively.

Six principal components explain $65.6 \%$ of the total variance between the extracted data. The first principal component couples the climate-orographic complex and explains $20 \%$ of the total variance. It accounts for the coupled system between elevation, temperature and rainfall. Elevation is inversely related to temperature and directly related to rainfall. It also supports the assumption that mesoscale processes which relies on orographic forces controls the local climate. The second, third and fourth principal components show inter-correlations between the same set of variables i.e. rainfall, NDVI and forested areas respectively. Principal components five and six, though explain only $7 \%$ and $6 \%$ of the variance respectively, combine factors which include aspect, forested area, slope and soil potential for agriculture which are important for the ecological systems and use of the land.

For the future climate, 6 principal components accounted for $69 \%$ of the total variance. The coupled climate-orographic complex still remains the controlling system and accounts for about $24 \%$ of the total variance. The second principal component establishes inter-relationship between the forested areas in two different periods, and the third principal component establishes the direct positive feedback between rainfall and protected areas.

\subsection{Spatial Pattern of the Controlling Systems}

The dominance of 'climate-terrain' complex on the local climate system is unassailable in both present and projected future climates. In both cases, elevation exerts positive influence on rainfall and negative influence on temperature. This pattern predominates from the southeast to northwest corridor and it is more pronounced in areas south of the city of Ilorin and around 'Oke-ogun' areas. The seasonal analyses suggest that this pattern predominates for present and future climates in DJF (Figure 3), MAM (Figure 4), SON (Figure 5) and for the annual average (Figure 7). The system is reversed in the monsoon season of JJA (Figure 6) when the inland basins across the Niger and northeast corridor experi- 
Table 3. Extracted principal components for present climate.

\begin{tabular}{lcccccc}
\hline & \multicolumn{5}{c}{ Component } \\
\hline \multicolumn{1}{c}{ Variables } & 1 & 2 & 3 & 4 & 5 & 6 \\
Aspect & 0.129 & -0.116 & 0.220 & -0.138 & 0.621 & -0.287 \\
Slope & -0.075 & 0.156 & 0.236 & 0.274 & 0.014 & -0.534 \\
Elevation & -0.818 & -0.018 & 0.292 & 0.063 & 0.059 & 0.060 \\
Population density & -0.168 & 0.234 & -0.062 & 0.289 & -0.062 & 0.312 \\
Soil potential for agric & 0.099 & 0.081 & 0.320 & 0.130 & 0.119 & 0.663 \\
Distance to water & -0.076 & -0.023 & 0.111 & 0.534 & -0.017 & 0.154 \\
Protected areas & 0.175 & 0.215 & -0.292 & 0.503 & -0.135 & -0.001 \\
NDVI for 1986 & -0.210 & -0.001 & 0.770 & 0.156 & -0.059 & -0.026 \\
NDVI for 2006 & -0.096 & 0.156 & 0.756 & -0.195 & 0.018 & 0.041 \\
Average Tmax for 1986 & 0.958 & 0.033 & -0.045 & 0.050 & 0.028 & 0.057 \\
Average Tmax for 2006 & 0.961 & -0.037 & -0.049 & 0.087 & -0.007 & 0.054 \\
Average rainfall for 1986 & 0.125 & 0.931 & 0.008 & -0.005 & -0.024 & -0.019 \\
Average rainfall for 2006 & -0.650 & 0.690 & 0.069 & -0.045 & 0.056 & -0.013 \\
Disturbance index for 1986 & -0.162 & -0.063 & -0.030 & 0.097 & 0.760 & 0.292 \\
Disturbance index for 2006 & 0.055 & -0.200 & 0.126 & 0.642 & 0.215 & -0.117 \\
Forested areas in 1986 & 0.001 & -0.090 & 0.465 & -0.176 & -0.660 & -0.019 \\
Forested areas in 2006 & -0.121 & -0.058 & 0.393 & -0.681 & -0.070 & 0.136 \\
Long-term mean rainfall & -0.048 & 0.915 & 0.097 & 0.007 & -0.080 & 0.035 \\
\hline
\end{tabular}

Table 4. Extracted principal components for future climate (2046-2065).

\begin{tabular}{lcccccc}
\hline & \multicolumn{5}{c}{ Component } \\
\hline \multicolumn{1}{c}{ Variables } & 1 & 2 & 3 & 5 & 6 \\
Aspect & -0.035 & -0.094 & 0.431 & 0.383 & 0.052 & 0.387 \\
Slope & 0.133 & -0.150 & -0.199 & -0.208 & -0.031 & 0.756 \\
Elevation & 0.823 & -0.157 & 0.192 & -0.197 & -0.120 & 0.007 \\
Population Density & 0.151 & -0.285 & -0.286 & -0.049 & -0.197 & -0.446 \\
Soil potential for agriculture & -0.005 & -0.085 & 0.010 & 0.172 & -0.848 & 0.022 \\
Distance to water & -0.029 & -0.387 & -0.016 & -0.376 & -0.317 & -0.008 \\
Protected area & -0.241 & -0.406 & -0.504 & -0.085 & 0.108 & -0.039 \\
Disturbance index for 1986 & 0.100 & -0.535 & 0.438 & 0.421 & -0.152 & -0.077 \\
Disturbance index for 2006 & -0.182 & -0.523 & 0.217 & -0.372 & -0.110 & 0.173 \\
Forest area in 1986 & 0.112 & 0.640 & -0.086 & -0.482 & -0.267 & 0.058 \\
Forest area in 2006 & 0.295 & 0.654 & 0.288 & 0.157 & -0.243 & 0.005 \\
Long term average rainfall & 0.746 & -0.025 & -0.518 & 0.294 & -0.035 & 0.108 \\
Monthly average rainfall & 0.746 & -0.026 & -0.518 & 0.294 & -0.034 & 0.107 \\
Long term average Tmax & -0.867 & 0.114 & -0.292 & 0.207 & -0.169 & 0.093 \\
Mean monthly Tmax & -0.867 & 0.104 & -0.283 & 0.209 & -0.172 & 0.096 \\
\hline
\end{tabular}

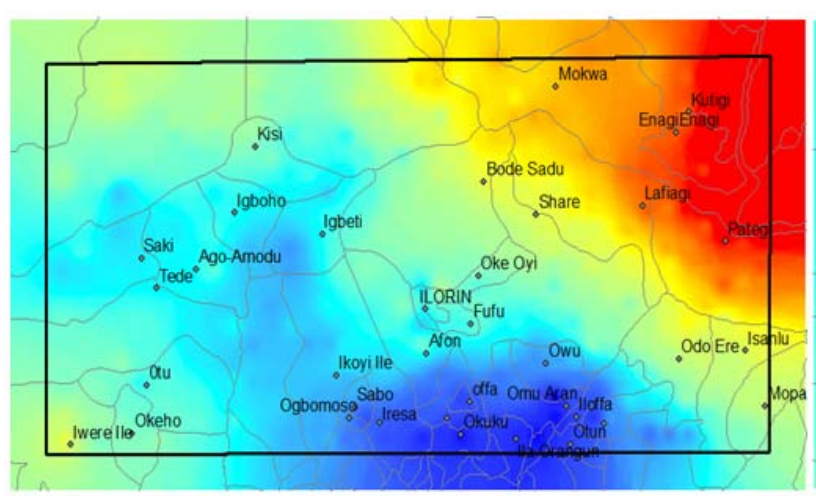

High : 1.934488

Low : -2.835830

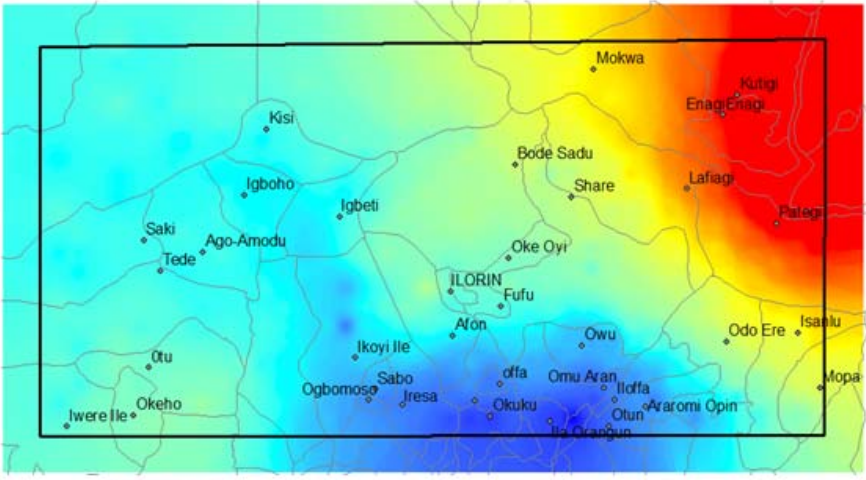

High : 3.94371

Low : -6.1369

Figure 3. DJF: Elevation varies directly with Rainfall and Inversely with Tmax in present (Left) and future (Right) climate. 


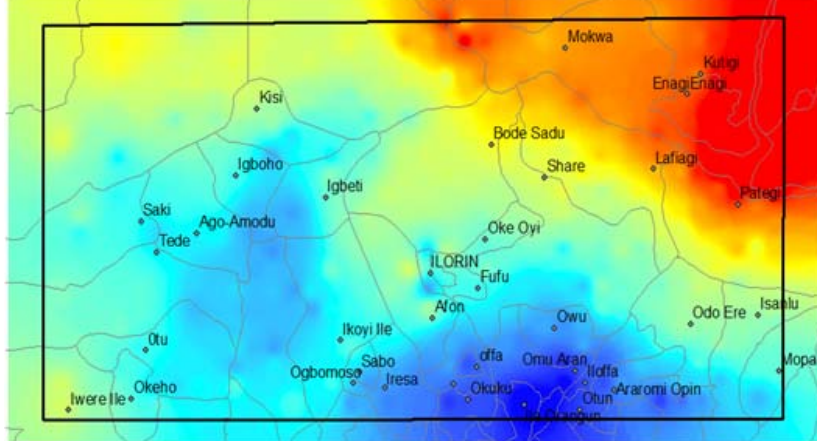

High : 2.182368

Low : -2.727426

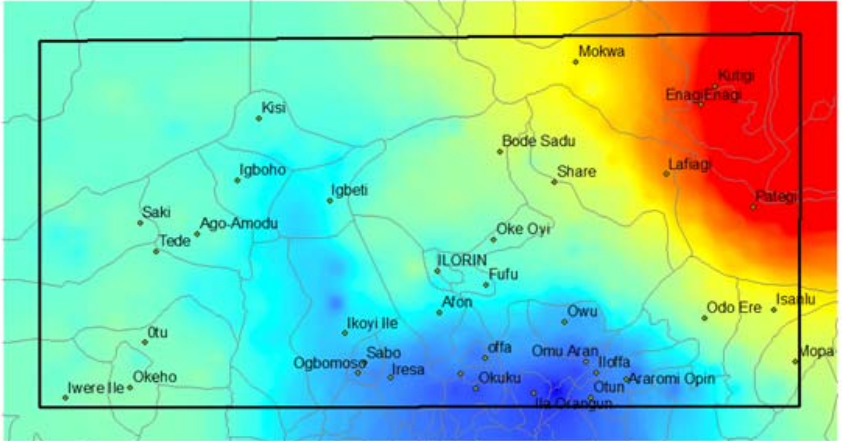

High : 3.888004

Low : -6.214900

Figure 4. MAM: Rainfall and Tmax vary inversely with Elevation for present climate (including NDVI) (Left) and in future climate (Right).
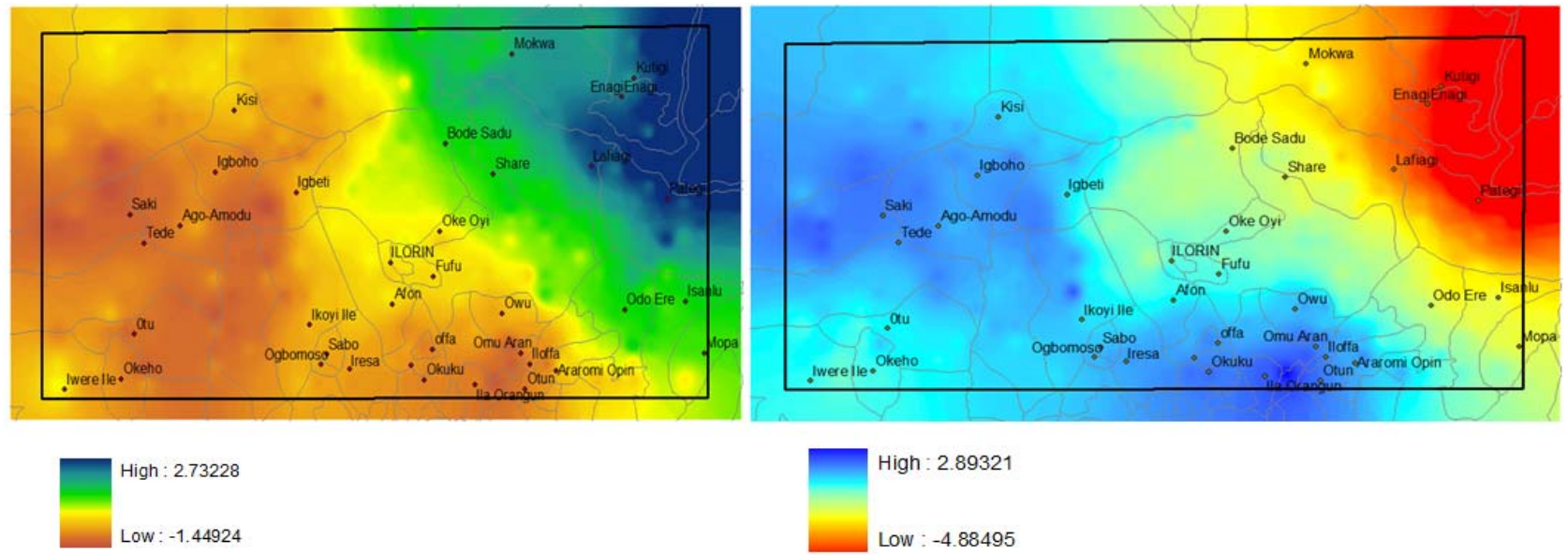

Figure 5. JJA: Rainfall and Tmax varies inversely with Elevation in present climate (Left), and future climate (Right)—when rainfall is no longer significant in the system.
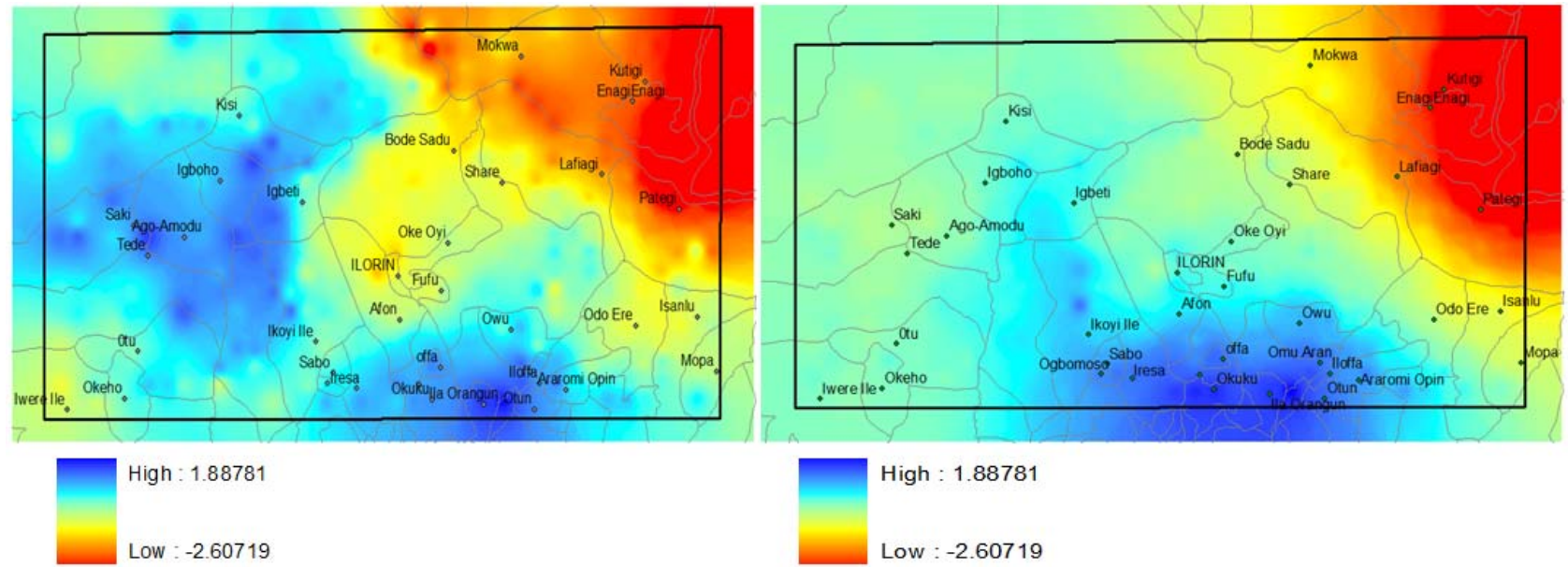

Figure 6. SON: Elevation Varies inversely with Tmax only in present climate (Left), and also directly with rain in future climate (Right). 


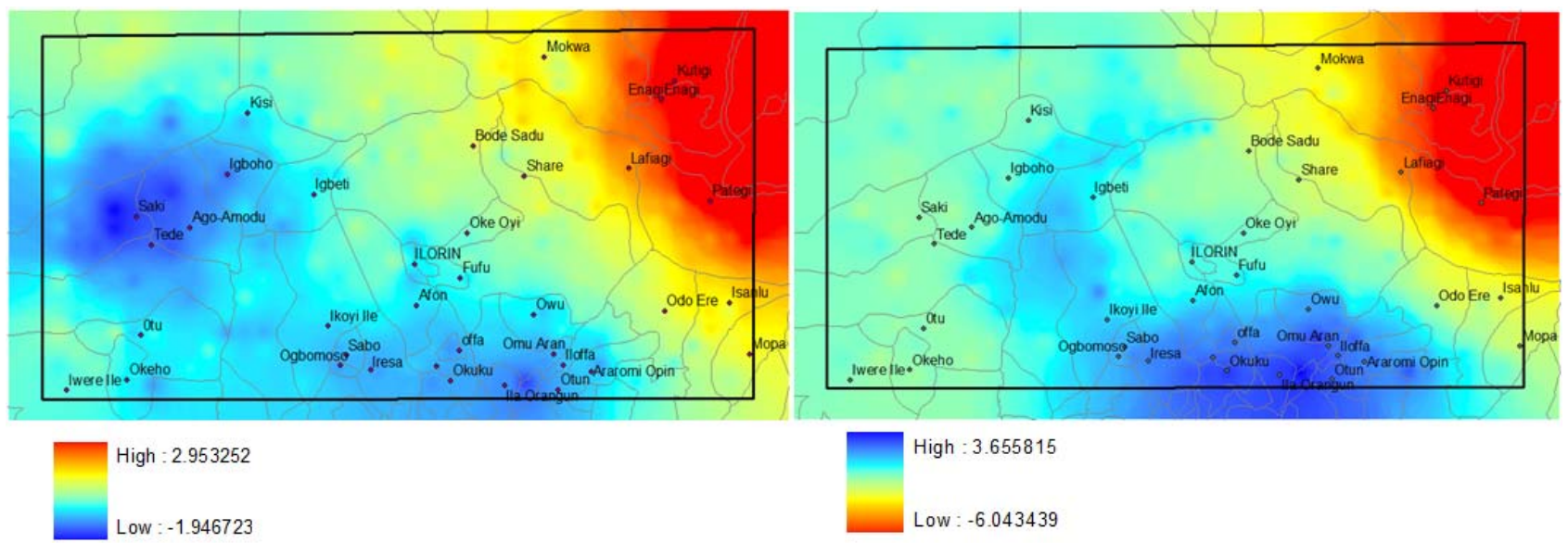

Figure7. The annual average: Rain and Tmax sensitivity to terrain in Present climate (-Elevation, - rain, +Tmax) (Left), and future climate (+Elevation, +rain, -Tmax) (Right).

ence higher rainfall and cooler temperature. Onset of rains in the southeast to northwest corridor is around April and most of the early rains are from mesoscale processes, thus giving the area a double peak rainfall in June and September. Incidentally, the agricultural landuse around the southeast to northwest corridor is dominated by rainfed small-holder root, tuber and cereal cultivation which are well suited to the optimum rainfall and lower temperature that prevail in this axis. On the other hand, onset of rains in the inland basins across the Niger is around May which coincides with the approach of the WAM. Peak rainfall is received in August, the same time when 'the little-dry season' pervades the southeast to northwest corridor. These feedbacks also contrast the general notion of a regular rainfall gradient that decreases with latitude in the Nigerian savannah.

This spatial pattern is projected to continue in future climate but with diminishing influence. While the system is projected to become pronounced in the highland areas located at the edge of the rainforest zone in the southeast axis, its influence around the northwest corridor especially in 'Okeogun' areas will diminish. This may have severe implication for large rural population that depends on the system for livelihood.

The expected upturn of the system in JJA will also become severely weakened in future scenario (Figure 5) because rainfall will no longer be significant in the system. A cool temperature without significant rainfall is expected to pervade the inland basins across the Niger. This will also pose serious implications for rural livelihoods in areas around the inland basins in the northeast axis that rely on the up-turn of the system in JJA to optimize their peasant agriculture.

The pattern of influence of terrain on local climate and the resulting eco-climatic complexes was compared with the present pattern of distribution of rural communities and the drainage pattern. The distribution of rural settlements across space is clustered (average nearest neighbour index: $=0.58$ and $\mathrm{Z}$ score $=-39.21 \mathrm{Std}(\mathrm{p}<0.01))$ around the areas where the terrain positively influences the climate for most seasons. This suggests a strong feedback between the rural livelihood systems and the local climate system. It also suggests that the 'climate-positives' of the southeast to northwest corridor has long been recognized by local communities as ecoclimatic asset on which their livelihood depends. It also underscores the importance of incorporating indigenous knowledge into climate change mitigation and adaptation planning. The integration of the local climate system maps with the drainage pattern also suggests that this eco-climatic asset is the nerve center for the drainage systems of western Nigeria. It is the headwaters for major rivers catchments including Okpara, Oyan, Ogun, Oba, Oshun, Asa and Ero Rivers that drain the western Nigeria. This suggests that the local climate system produces distinct space-specific ecological and natural resource systems which directly and indirectly support livelihoods and other provisioning services for very large population in the savannah.

\section{Discussions}

Climate change mitigation options may range from local, regional to global, but adaptation is highly localized, place-specific and sometimes contextual. Rural livelihoods are also localized and rely mainly on local natural resource systems created by local climate-positives. Large population of peasant farmers and pastoralists in dry and semi-dry environments depend on the interaction between climate and natural resources for survival. Climate sensitive but well managed natural resource sys- 
tems support sustainable livelihoods and also enhance long-term climate regulation services. If these resource systems are poorly managed, they tend to exacerbate climate change impacts. The pattern created by the interaction between terrain, land cover and the local climate varies spatio-temporally. In the present climate, the climate-positive produces eco-climatic complex which stretches from southeast to northwest corridor and particularly pronounced around the 'Oke-ogun' in the west-central area of the region. The 'Oke-ogun' area is locally acknowledged as the food basket of western Nigeria because its highly productive land supports production of arable crops including yam, cassava, maize and sorghum. This area has also witnessed significant rural-to-rural migration in recent past. Conflict over land resources especially between sedentary cultivators and pastoralists is becoming rampant. Because the climate-positive advantage is projected to weaken in future, severe consequences on livelihoods and increase in resource conflict are also likely. A reversed rural-to-rural migration may also upset existing socio-economic balance and increase land resource conflicts in newly suitable lands.

The people in the inland basins across the Niger River around the northeast axis also depend on peasant rainfed agriculture for livelihood. Farming is programmed to take full advantage of the rainy months except in the floodplains. The situation may become more critical in future because the expected reversal which will likely lead to the weakening of the MCS in the southeast to northwest corridor is projected to become more unstable, causing less rainfall in JJA in the northeast axis than presently experience. This suggests these areas will become drier in future. This will no doubt challenge existing traditional agricultural systems. Innovative adaptive capacities and strategies are therefore required to avert food insecurity.

The pattern exhibited by location of communities suggests the livelihood systems are directly connected to the eco-climatic corridors. In essence, the terrain system modifies the local climate to produce favorable condition that supports rainfed agriculture for most seasons of the year. On the other hand, communities located in the inland basin across the Niger River rely mainly on the upturning of the system in JJA before planting their crops. This could be responsible for why flood plain agriculture and small scale irrigation farming is common in the inland basins than the southeast to northwest corridor. The eco-climatic complex as a natural resource system area also creates a super watershed that drains the entire western Nigeria. This suggests that ecological breakdown resulting from climate change, which is suggested by the future climate scenario, may spell disaster for human livelihoods as well as water availability. The green and blue water footprint in the region may in future become the footprint of fierce resource competition.

Aggressive vegetation and albedo enhancement strategies to restore moisture and energy balances, maintain ecological function and enhance climate regulation services may be necessary to guarantee the local climate system. The eco-climatic resources together with the river catchments constitute important climate sensitive natural resource system that needs to be protected. This makes it attractive to the reduced emission from deforestation and land degradation (REDD) and clean development mechanisms (CDM) initiatives.

\section{Conclusions}

The study has attempted to provide insights into the relations between the local climate system and the controlling factors using the PCA. The principal factors show a strong coupling between the climatic elements and the terrain which suggests the dominance of the mesoscale convective systems. The variation in the spatial pattern of influence is consistent with the locational pattern of communities and the livelihood systems which suggests dependence on the eco-climatic resource complex. While the observed pattern is projected to continue in future, the spatial influence will severely diminish and some areas especially around 'Oke-ogun' that presently support large population and viable rural livelihoods may be negatively affected. The areas of strong positive climate-terrain feedback corridor also correspond to a super catchment for the major drainages of western Nigeria. We conclude that these eco-climatic complexes constitute an important natural resource system for climate change mitigation and adaptation in the wooded savannah of western Nigeria.

\section{Acknowledgments}

This research was carried out under the African Climate Change Fellowship Programme (ACCFP) postdoctoral fellowship awarded to MF. The ACCFP is supported by a grant from the Climate Change Adaptation in Africa (CCAA) jointly funded by IDRC and DFID. The International START Secretariat is the implementing agency in collaboration with the Institute of Resource Assessment (IRA) of the University of Dar es Salaam and the African Academic of Sciences (AAS).

\section{REFERENCES}

[1] S. D. Solomon, D. Qin, M. Manning, R. B. Alley, T. Berntsen, N. L. Bindoff, Z. Chen, A. Chidthaisong, J. M. Gregory, G. C. Hegerl, M. Heimann, B. Hewitson, B. J Hoskins, F. Joos, J. Jouzel, V. Kattsov, U. Lohmann, T. Matsuno, M. Molina, N. Nicholls, J. Overpeck, G. Raga, 
V. Ramaswamy, J. Ren, M. Rusticucci, R. Somerville, T. F. Stocker, P. Whetton, R. A. Wood, D. Wratt (2007): "Technical Summary," In: S. Solomon, D. Quin, M. Manning, Z. Chen, M. Marquis, K. B. Averyt, M. Tignor, Miller H. L., Eds., Climate Change 2007: The Physical Science Basis. Contribution of Working Group I to the Fourth Assessment Report of the Intergovernmental Panel on Climate Change, Cambridge University Press, Cambridge, Cambridge and New York, 2007.

[2] S. Nicholson, "Land Surface Processes and Sahel climate," Reviews of Geophysics, Vol. 38, No 1, 2000, pp. 117-339. doi:10.1029/1999RG900014

[3] E. A. Afiesimama, J. S Pal, B. J. Abiodun, W. J. Gutowski and A. Adedoyin, "Simulation of West African monsoon using the RegCM3. Part I: Model Validation and Interannual Variability." Theoretical and Applied Climatology, Vol. 86, 2006, pp. 23-37. doi:10.1007/s00704-005-0202-8

[4] B. J. Abiodun, J. S. Pal, E. A. Afiesimama, W. J. Gutowski and A. Adedoyin, "Simulation of West African monsoon using RegCM3 Part II: Impacts of Deforestation and Desertification, Theoretical and Applied Climatology, Vol. 93, 2008, pp. 245-261.

doi:10.1007/s00704-007-0333-1

[5] C. Müller, "Climate Change Impact on Sub-Saharan Africa: An Overview and Analysis of Scenarios and Models," Deutsches Institut für Entwicklungspolitik, Vol. 3, 2009.

[6] T. O. Odekunle, E. E. Balogun and O. O. Ogunkoya, "On the Prediction of Rainfall Onset and Retreat Dates in Nigeria." Theoretical and Applied Climatology, Vol. 81, 2005, pp. 101-112. doi:10.1007/s00704-004-0108-x

[7] M. Fasona, A. Omojola, O. Adeaga and D. Dabi, "Aspects of Climate Change and Resource Conflicts in the Nigeria Savannah," Report of IPCC/TGICA Expert Meeting on Integrating Analysis of Regional Climate Change and Response Options, Fiji Island, 2007, pp. 45-55.

[8] B. C. Hewitson and R. G. Crane, "Consensus between GCM Climate Change Projections with Empirical Downscaling: Precipitation Downscaling over South Africa," International Journal of Climatology, Vol. 26, 2006, pp. 1315-1337. doi:10.1002/joc. 1314

[9] T. J. Stohlren, T. N. Chase, R. A. Pielke, T. G. Kittel and J. S. Baron, "Evidence that Local Land Use Practices Influence Regional Climate, Vegetation, and Stream Flow Patterns in Adjacent Natural Areas," Global Change Biology, Vol. 4, No. 5, 1998, pp. 495-504. doi:10.1046/j.1365-2486.1998.t01-1-00182.x

[10] R. A. Pielke, J. Adegoke, A. Beltran-Przekurat, C. A. Hiemstra, J. Lin, U. S. Nair, D. Niyogi and E. Nobis, “An Overview of Regional Land-Use and Land-Cover Impacts on Rainfall," Tellus B, Vol. 59, No 3, 2007, pp. 587-601. doi:10.1111/j.1600-0889.2007.00251.x

[11] NDP-UNEP, "Mainstreaming Poverty-Environment Linkages into Development Planning: A Handbook for Practitioners," 2009. http://www.unpei.org

[12] J. B. Omotosho and J. Abiodun, "A Numerical Study ofMoisture Build-Up and Rainfall over West Africa," Me teorologucal Applications, Vol. 14, 2007, pp. 209-225.

[13] R. L. Wilby, S. P. Charles, E. Zorita, B. Timbal, P. Whetton and L. O. Mearns, "Guidelines for Use of Climate Scenarios Developed from Statistical Downscaling Methods," 2004.

http://www.ipcc-data.org/guidelines/dgm_no2_v1_09_20 04.pdf

[14] W. A. Hoffmann and R. B. Jackson, "Vegetation-Climate Feedbacks in the Conversion of Tropical Savannah to Grassland", Journal of Climate, Vol. 13, No. 9, 2000, pp. , 1593-1602

[15] G. Bucini and E. F. Lambin, "Fire Impacts on Vegetation in Central Africa: A Remote-Sensing-Based Statistical Analysis," Applied Geography, Vol. 22, No.1, 2002, pp. 27-48. doi:10.1016/S0143-6228(01)00020-0

[16] M. Kottek, J. Grieser, C. Beck, B. Rudolf and F. Ru, "World Map of the Köppen-Geiger Climate Classification Updated," Meteorologische Zeitschrift, Vol. 15, No. 3, 2006, pp. 259-263.

[17] C. Neely, S. Bunning and A. Wilkes, "Review of Evidence on Drylands Pastoral Systems and Climate Change: Implications and Opportunities for Mitigation and Adaptation," FAO, Rome, 2009.

[18] J. F. K. Akinbami, A. T. Salami and W. O. Siyanbola, "An Integrated Strategy for Sustainable Forest-EnergyEnvironment Interactions in Nigeria," Journal of Environmental Management, Vol. 69, No. 2, 2003, pp. 115-128. doi:10.1016/S0301-4797(03)00083-5

[19] M. J. Fasona and A. S. Omojola, "Climate Change, Human Security and Communal Clashes in Nigeria," Proceedings International Workshop on Human Security and Climate Change, Asker, Oslo, 21-23 June 2005.

[20] E. E. Obioha, "Climate Change, Population Drift and Violent Conflict over Land Resources in North-eastern Nigeria," Journal of Human Ecology, Vol. 23, No. 4, 2008, pp. 311-324.

[21] S. R. Adisa and O. A. Adekunle, "Farmer-Herdsmen Conflicts: A Factor Analysis of Socio-Economic Conflict Variables among Arable Crop Farmers in North Central Nigeria," Journal of Human Ecology, Vol. 30, No. 1, 2010, pp. 1-9.

[22] J. Pinzon, "Using HHT to Successfully Uncouple Seasonal and iIterannual Components in Remotely Sensed Data," Proceedings SCI 2002, Orlando, 14-18 July 2002.

[23] J. Pinzon, M. E. Brown and C. J. Tucker, "Satellite Time Series Correction of Orbital Drift Artifacts Using Empirical Mode Decomposition," In: N. Hubert-Huang, Ed., Transform: Introduction and Applications, World Scientific, 2004.

[24] C. J. Tucker, J. E. Pinzón, M. E. Brown, D. Slayback, E. W. Pak, R. Mahoney, E. Vermote and N. El Saleous, "An Extended AVHRR 8-km NDVI Data Set Compatible with MODIS and SPOT Vegetation NDVI Data," International Journal of Remote Sensing, Vol. 26, No. 20, 2005, pp. 4485-4498.

[25] A. Anyamba and C. J. Tucker, "Analysis of Sahelian Vegetation Dynamics Using NOAA-AVHRR NDVI Data 
from 1981-2003." Journal of Arid Environments, Vol. 63, 2005, pp. 596-614. doi:10.1016/j.jaridenv.2005.03.007

[26] D. A. Stow, A. Hope, D. McGuire, D. Verbyla, J. Gamon, F. Huemmrich, S. Houston, C. Racine, M. Sturm, K. Tape, I. Hinzman, K. Yoshikawa, C. Tweedie, B. Noyle, C. Silapaswan, D. Douglas, B. Griffith, G. Jia, H. Epstein, D. Walker, S. Daeschner, A. Petersen, L. Zhou and R. Myneni, "Remote Sensing of Vegetation and Land-Over Change in Arctic Tundra Ecosystems," Remote Sensing of Environment, Vol. 89, No. 3, 2004, pp. 281-308. doi:10.1016/j.rse.2003.10.018

[27] C. S. R. Neigh, C. J. Tucker and J. R. G. Townshend, "North American Vegetation Dynamics Observed with Multi-Resolution Satellite Data," Remote Sensing of Environment, Vol. 112, No. 4, 2008, pp. 1749-1772. doi:10.1016/j.rse.2007.08.018

[28] K. H. Cook and E. K. Vizy, "Coupled Model Simulation of the West African Monsoon Systems: Twentieth- and Twenty-First-Century Simulations," Journal of Climate, Vol. 19, 2006, pp. 3681-3703. doi:10.1175/JCLI3814.1

[29] J. R. Eastman, "Idrisi Taiga Guide to Image Processing," Clark Labs, Worcester, 2009.

[30] K. G. Paterson, J. Sagady, D. Hooper, S. B. Bertman, M. A. Carrol and P. B. Shepson, "Analysis of Air Quality Data Using Positive Matrix Factorization," Environmental Science \& Technology, Vol. 33, No. 4, 1999, pp. 635-641.

[31] M. Statheropoulos, N. Vassiliadis and A. Pappa, "Principal Component and Canonical Correlation Analysis for
Examining Air Pollution and Meteorological Data," Atmospheric Environment, Vol. 32, No. 6, 1998, pp. 1087-1095.

[32] J. L. Moore, L. Manne, T. Brooks, N. D. Burgess, R. Davies, C. Rahbek, P. Williams and A. Balmford, "The Distribution of Cultural and Biological Diversity in Africa," Proceedings of Royal Society, Vol. 269, No. 1501, 2002, pp. 1645-1653.

[33] R. Engler, A. Guisan and L. Rechsteiner, "An Improved Approach for Predicting the Distribution of Rare and Endangered Species from Occurrence and Pseudo-Absence Data," Journal of Applied Ecology, Vol. 41, No. 2, 2004, pp. 263-274. doi:10.1111/j.0021-8901.2004.00881.x

[34] C. Reimanna, C. Filzmoserb and R. G. Garrett, "Factor Analysis Applied to Regional Geochemical Data: Problems and Possibilities," Applied Geochemistry, Vol. 17, No. 3, 2002, pp. 185-206. doi:10.1016/S0883-2927(01)00066-X

[35] D. Love, D. Hallbauer, A. Amos and R. Hranova, "Factor Analysis as a Tool in Groundwater Quality Management: Two Southern African Case Studies," Physics and Chemistry of the Earth, Vol. 29, No. 15-18, 2004, pp. 1135-1143.

[36] A. Facchinelli, E. Sacchi and L. Mallen, "Multivariate Statistical and GIS-Based Approach to Identify Heavy Metals in Soils," Environmental Pollution, Vol. 114, No. 3, 2001, pp. 313-324. doi:10.1016/S0269-7491(00)00243-8 